\title{
Privação relativa e ativismo em protestos no Brasil: uma investigação sobre o horizonte do possível
}

Clarice Mendonça

Mario Fuks

\section{Introdução}

Estudos de meados do século XX destacam a percepção de privação relativa como motivação que, associada a outras condições, é capaz de impulsionar a participação em todo tipo de atividades contestatórias, como protestos, rebeliões e revoltas. Nos estudos sobre participação política, a privação relativa vem sendo utilizada para entender situações muito comuns em que somente a privação absoluta, mesmo que extrema, não é capaz de levar o indivíduo a protestar por melhorias. Inversamente, a teoria também é usada para explicar o aumento da participação em protestos em contextos de prosperidade e melhora das condições de vida.

O conceito clássico de privação relativa envolve o reconhecimento de carências em relação a outros e a expectativa de que haja possibilidades para o alcance do objeto ou condição desejados (Runciman, 1966). Os primeiros estudos sobre o tema colocavam foco no sentimento da privação em relação à condição experimentada por outros. A teoria da privação relativa valeu-se, nesse sentido, das descobertas da teoria dos grupos de referência, que postula que o indivíduo é socialmente construído de acordo com os grupos que toma por referência, tanto aqueles dos quais faz parte quanto aqueles aos quais não pertence (Merton, 1970). Em desenvolvimentos posteriores, principalmente na ciência política, o componente relativo passa a referir-se também à comparação que o indivíduo faz entre suas expectativas de ganho ou patamar social em que deseja estar e as respectivas capacidades reais de realização, ou seja, à comparação entre seus desejos e sua situação atual (Santos, 2006; Gurr, 1971). Toma importância, a partir de então, a percepção das possibilidades de realização daquilo que se almeja, o chamado horizonte do possível (Santos, 2006).

A privação relativa foi utilizada por Santos (2006) para entender um quadro de aparente contradição entre os altos níveis de privação, pelos quais passa considerável parcela da população brasileira, e os relativamente baixos níveis de protestos políticos no Brasil. O autor defende que um quadro de inércia social vivido pelo Brasil, caracterizado, de maneira geral, pela perpetuação da concentração de renda e de pessoas, respectivamente, nos extremos superior e inferior, faz com que a magnitude do horizonte do possível seja reduzida: "pode haver inveja, paralisante, mas nenhum miserável 
imagina chegar sequer próximo ao topo" (Santos, 2006, p. 174). Se não há expectativas realistas de mudanças significativas, as pessoas tendem a manter seus desejos dentro da modesta pauta do realizável. Quando, entretanto, acréscimos de riqueza são mais equitativamente distribuídos, há um aumento no horizonte de possibilidades e as expectativas de ganho descolam-se da curva dos ganhos reais, adquirindo velocidade própria e maior.

O mecanismo das expectativas crescentes ou da perfectibilidade contínua e indefinida do homem (Tocqueville, 2009) explica por que as pessoas, ao perceberem mudanças no fluxo de aquisição material, passam a ter os seus desejos realocados a maiores distâncias dos ganhos reais. Ou seja, ao perceberem maiores possibilidades de mudança, as pessoas tenderiam a demandar ainda mais.

Aqui colocamos o primeiro ponto de investigação a respeito da teoria de Santos (2006) para os protestos (ou ausência deles) no Brasil. O autor elabora sua tese a partir da análise de dados agregados no nível do país, ao longo do tempo, para demonstrar o imobilismo e a relação entre o reduzido horizonte de possibilidades e a ausência de movimentos contestatórios no Brasil. Será essa relação verificável no nível individual? Defendemos que a conversão das condições objetivas em percepção individual é uma componente-chave na explicação do comportamento político. A questão de fundo é que essa passagem da dimensão objetiva para a subjetiva não ocorre de forma automática, nem necessária. A percepção sobre as condições objetivas varia de acordo com um grande número de fatores, incluindo atributos individuais e sociais, não coincidindo muitas vezes com essas próprias condições. Ao testarmos o impacto, no nível individual, da ampliação do horizonte do possível sobre a participação em protestos, seremos capazes de avaliar com maior precisão a relação entre esses dois fenômenos.

A percepção é o mecanismo específico mediante o qual as condições objetivas se convertem em privação relativa, incidindo, portanto, no horizonte do possível. Apesar de depender de condições objetivas, esse fenômeno que combina privação e ampliação do horizonte só é consumado quando essas condições são acompanhadas de mudança na percepção, constituindo as bases subjetivas da privação relativa.

O outro ponto de investigação relaciona-se ao caminho percorrido pela privação relativa até sua tradução em comportamento. O aumento do hiato entre o patamar desejado e as capacidades atuais de realização foi apontado como promotor de maiores propensões ao envolvimento em atividades contestatórias, em especial protestos e rebeliões (Santos, 2006; Gurr, 1971). Os primeiros estudos psicológicos da privação relativa demonstravam que os níveis de insatisfação com a situação vivida eram uma função do sentimento de carências injustas em relação aos outros e que os comportamentos agressivos de toda natureza teriam sua origem na insatisfação (Gurr, 1968). Nesse sentido, a insatisfação seria o fator motivador do comportamento. De acordo com o atual conceito de privação relativa, entende-se que a insatisfação seja um 
componente associado à comparação com a situação de outros e à percepção da possibilidade de alcançar melhores condições. As pessoas que se veem em situação de inferioridade e que vislumbram possibilidades de alcançar melhores posições, ou seja, que se encontram em situação de privação relativa, seriam mais insatisfeitas com sua posição e mais motivadas a buscar mudanças. Com isso, fica a questão: a insatisfação confirma-se como um importante fator para entender a relação entre a privação relativa e os protestos?

Este artigo analisa os dados da pesquisa Barômetro das Américas de 2012 representativos para a população brasileira e busca cumprir dois objetivos: avaliar se a relação entre a percepção individual do horizonte de possibilidades e o ativismo em protestos se confirma na realidade brasileira e testar se a interação entre a insatisfação individual e a privação relativa gera maiores níveis de comportamento contestatório. Para isso, na seção "A privação relativa como explicação dos protestos", é apresentado o desenvolvimento do conceito de privação relativa e das teorias que o associam à participação política. Em seguida, são relatados o problema, as hipóteses e a metodologia de investigação. Por fim, apresentam-se os resultados das análises descritivas e multivariadas e as conclusões do estudo.

\section{A privação relativa como explicação dos protestos}

O registro mais antigo da utilização do conceito de privação relativa associado à ampliação do horizonte de possibilidades para explicação do comportamento humano é atribuído a Tocqueville (2009), em O Antigo Regime e a Revolução, publicado pela primeira vez em 1856. Apesar de não realizar uma elaboração conceitual detalhada do mecanismo da privação relativa, o autor o utiliza para explicar o porquê de a Revolução ter ocorrido especificamente na França.

A partir de análises das condições da França e de outros países da Europa nos momentos que antecederam a Revolução Francesa, Tocqueville conclui que o início de um processo de melhorias de condições é seguido pela ânsia de conseguir mais e maiores mudanças. $O$ autor chega a essa conclusão ao observar que as partes da França que seriam o principal foco da Revolução Francesa são precisamente aquelas em que os avanços em direção à república são mais evidentes ou a derrocada do Antigo Regime já estava mais avançada. Nesses locais, havia mais liberdade, a corveia pessoal (trabalho compulsório para o governo) já havia desaparecido e a cobrança de impostos era mais moderada. Inversamente, precisamente onde o Antigo Regime se fazia mais presente, a população resistiu mais violentamente e por mais tempo à Revolução. De tal forma "que se diria que os franceses consideraram sua posição tanto mais intolerável quanto melhor ela se tornava" (Tocqueville, 2009, p. 194). 
Esse modelo explicativo permite considerar uma relação entre o processo de desenvolvimento social vivido pelo Brasil na última década e o ativismo em protestos. Seria de supor, portanto, que acréscimos de riqueza mais equitativamente distribuídos, como vividos na última década no Brasil, seriam seguidos por um movimento no horizonte temporal dos desejos. Isso se traduz, para aqueles que ingressam no fluxo da aquisição material, em expectativas crescentes, um dos componentes motivadores das atividades contestatórias.

O esboço do mecanismo da privação relativa feito por Tocqueville aproxima-se de apenas um eixo do conceito como é utilizado atualmente, o do horizonte do possível (Santos, 2006) ou das expectativas (Gurr, 1971). Esse componente também estava presente, de acordo com Merton (1970), na primeira vez em que a ideia de privação relativa foi operacionalizada em pesquisas sistemáticas, como variável interpretativa interveniente para entender o comportamento, na obra The American soldier. A privação relativa, como apresentada na obra que resultou das pesquisas sobre as atitudes e opiniões de oficiais norte-americanos, incluía os conceitos sociológicos de "estrutura social de referência", "padrões de expectativa" e "definições da situação" (Merton, 1970).

Esses três eixos estão presentes na definição de Runciman (1966) sobre privação relativa, pioneiro em apresentar um conceito completo e sistematizado. O autor propõe um esclarecedor esquema lógico das quatro precondições da privação relativa, que tem sido extensamente replicado na literatura sobre o tema e que torna o conceito mais amplo, aplicável a qualquer situação em que se configura um objeto de desejo. Segundo ele, para que um indivíduo esteja em estado de privação relativa, ele: (1) vislumbra um objeto de desejo, (2) não possui esse objeto de desejo, (3) percebe que outras pessoas possuem o objeto desejado, (4) acredita que obter o objeto de desejo seja realizável. A combinação dos três primeiros estágios é necessária para ocasionar a insatisfação com a situação, gerando sensações de injustiça, raiva ou revolta (Runciman, 1966; Merton, 1970; Gurr, 1971).

Com a obra de Gurr (1971), a privação relativa sai da lista de motivações do comportamento violento do campo da psicologia para figurar entre os condicionantes da participação política contestatória. Os estudos da ciência política sobre o efeito da privação relativa sobre os protestos, a partir disso, não colocam foco nos eixos da privação absoluta e da comparação com outros. Assumem, por outro lado, que esses dois fatores estão correlacionados com a insatisfação e que esta sim é a responsável pelo impacto na atividade política. Ao falar de privação relativa, grande parte dos estudos da ciência política está referindo-se à relação da insatisfação individual e da percepção de possibilidades de alcançar melhorias ou expectativas de melhorias.

A privação relativa diferencia-se, entretanto, da inveja social, a percepção de que aquilo que é invejado não é alcançável. Esse entendimento é traduzido pela inclusão do elemento que Santos (2006) tão bem denominou de horizonte do possível, a percepção 
de que possa ser possível alcançar a mudança para um estágio superior de vida, envolvendo as percepções individuais do progresso e da mobilidade social.

Interessa-nos aqui especialmente a interação do horizonte do possível com a insatisfação individual. O horizonte do possível, eixo do conceito clássico de privação relativa (Runciman, 1966) que foi assim batizado por Santos (2006), é capaz de fornecer explicações para situações que apresentam ao mesmo tempo uma melhoria das condições de vida e um aumento dos protestos políticos. Para que a insatisfação impulsione a participação em protestos, é necessário que o indivíduo perceba que é possível alcançar melhores condições (Santos, 2006). O impacto da insatisfação individual sobre os protestos é potencializado na presença da percepção dessa possibilidade de diminuir as carências originais, geradoras da insatisfação. O horizonte do possível é então apresentado como uma variável que interage com a insatisfação gerada pela privação relativa, causando assim maiores níveis de participação em protestos. Aquelas pessoas que estão insatisfeitas com certos aspectos da vida sentem-se mais compelidas a participar em protestos quando veem que certos aspectos da vida social estão melhorando. Por isso, esse eixo da privação relativa tem sido usado para explicar por que as pessoas protestam mais à medida que as sociedades se tornam mais justas ou que certas condições objetivas apresentam melhorias significativas.

As análises de Tocqueville embasam as explicações de Santos (2006) para a ausência de rebeliões, no Brasil, fundamentadas na coexistência da modernização e enriquecimento do país, de um lado, e a manutenção das condições precárias de vida de um enorme contingente de pobres. Santos (2006) defende a ideia de que a população brasileira se encontra em inércia social da década de 1990 aos anos 2000. Dados sobre as taxas de atividade econômica por sexo, de escolarização por região e de rendimento médio por pessoas ocupadas são evidências da inércia social: a conservação da distribuição da força de trabalho masculina e feminina, a conservação das distâncias relativas entre as taxas de escolarização das regiões do Brasil e um retrato distributivo do número de pessoas por renda familiar per capita praticamente inalterado ao longo da década de 1990. Apesar disso, ou em contraste, as desigualdades na alocação da PEA por classes de salários são enormes. Segundo Santos, essa inércia social, caracterizada pela estagnação dos movimentos de migração entre as classes sociais, tem impacto no ativismo político mediado pela percepção da privação relativa.

O autor afirma, em consonância com Runciman (1966), que a privação relativa é também composta pelo "horizonte do possível", envolvendo um entendimento de que possa ser possível alcançar a mudança para um estágio superior de vida. Por isso, ela envolve também o progresso e a mobilidade social.

Santos (2006) ainda endossa a tese tocquevilliana de que acréscimos de riqueza mais equitativamente distribuídos são seguidos por um movimento no horizonte temporal dos desejos. Ou seja, ao suceder longo período de estagnação, aqueles que ingressam no 
fluxo da aquisição material sucumbem a um processo de expectativas crescentes. Quanto maior o ganho, após um período de estagnação, maiores as expectativas e, portanto, maior a taxa de privação relativa.

Santos faz, entretanto, uma qualificação na hipótese de Tocqueville: a mudança no sentido da acumulação e o nível de pobreza precisam ultrapassar certo limiar de sensibilidade social para que o hiato de privação seja percebido. Aquém de certas condições sociais, o horizonte do desejo, ou as expectativas, é ainda visto como inalcançável, não havendo, portanto, estímulo a novas demandas. Nesse contexto, os processos de melhoria de vida observados e a ampliação dos estados de privação relativa não teriam impacto algum sobre a participação em protestos.

Adotamos neste artigo o conceito clássico de privação relativa elaborado por Runciman (1966), que, como vimos, envolve três estágios: vislumbrar um objeto de desejo que não se possui; perceber que outros possuem esse objeto; entender que é possível alcançar esse objeto. O caso brasileiro parece nos oferecer uma oportunidade para testar a teoria da privação relativa. Apesar de o país ter se apresentado na última década como uma das economias mais fortes do mundo, os números do desenvolvimento social são desanimadores. Grande parcela de nossa população ainda vive situações de pobreza ou miséria. Há um forte déficit na prestação de serviços públicos mais básicos, como saúde, educação, transporte, moradia, saneamento, o que impacta significativamente na qualidade de vida das parcelas mais pobres. Sabe-se que o Brasil ainda conta com um dos maiores índices de desigualdade social do mundo, quadro que se repete também no âmbito da participação política. Tal como observado e atestado para o caso norte-americano, as condições socioeconômicas são as principais preditoras da participação política também no Brasil, configurando um quadro em que as vozes da participação política - que chegam aos representantes e instituições - formam um "coro de elite" (Verba, Schlozman e Brady, 2012).

Santos (2006) nos apresenta a combinação da insatisfação com o horizonte do possível como condição capaz de gerar protestos. Em sua análise, a falta do horizonte do possível é a causa do baixo ativismo em protestos no Brasil. As análises de Santos são feitas a partir de dados agregados sobre a mobilidade social e a participação política, somente para o Brasil. Com isso, ele não foi capaz de testar se a percepção do horizonte do possível e a participação política estão associadas na percepção individual. Para investigar essa relação, o presente artigo examina a percepção do indivíduo sobre suas possibilidades de melhorar de vida. Ao escolher o nível individual de análise para o horizonte do possível, acreditamos captar a presença desse mecanismo em indivíduos que de fato reconhecem efeitos da mudança ocorrida no país para sua própria vida. Trata-se de uma especificação do argumento de Santos: existe relação entre a percepção do horizonte do possível e a participação em protestos? A percepção do horizonte do 
possível, quando associada à insatisfação com as condições de vida, configura-se como um relevante preditor de protestos políticos no Brasil?

\section{Dados e método}

Utilizamos, neste artigo, dados do survey Barômetro das Américas de 2012, desenvolvido pelo Latin American Public Opinion Project (Lapop), instituto sediado na Vanderbilt University (EUA). O survey é aplicado a cada dois anos e tem o objetivo de medir valores democráticos e comportamento político nas Américas. Sua escolha para utilização no presente artigo se deveu, principalmente, por abranger as variáveis de interesse para análise da participação política e privação relativa. A edição de 2012 para o Brasil tem representatividade nacional para adultos em idade de votar e foi conduzida por meio de entrevistas realizadas entre os dias $1^{\circ}$ de março e 18 de abril daquele ano.

As amostras do Barômetro das Américas foram desenvolvidas usando um desenho probabilístico de estágios múltiplos, observando cotas no nível domiciliar. No Brasil, a amostra em 2012 foi de 1.500 indivíduos, com erro amostral de $\pm 2,5 \%$.

Os resultados empíricos deste artigo foram gerados a partir de métodos estatísticos descritivos e multivariados. Dada a natureza qualitativa binária da variável dependente ("Participou de protesto público ou manifestação nos últimos 12 meses?"), a técnica de análise multivariada escolhida foi a de regressão logística, apontada como a mais utilizada para tais tipos de dados (Long e Freese, 2001).

A esfera do horizonte do possível não é contemplada no survey com uma questão direta. A proxy aqui adotada é constituída a partir de duas perguntas: "Qual era a sua classe social há 8 anos atrás?" e "E hoje, o/a sr./sra. se descreveria como pertencendo à classe...?", e aproxima-se da mensuração feita por Santos (2006), que utilizou dados sobre a mobilidade social para caracterizar a percepção das possibilidades de melhoria de vida. O grupo de pessoas que declararam ter alcançado classes sociais superiores é relevante para a análise do horizonte do possível, pois quem declara ter feito o movimento ascendente muito provavelmente percebe que é possível melhorar de vida na atual conjuntura do país. A partir da comparação entre a classe que o indivíduo declarou ter nos oito anos anteriores à entrevista com a que declara pertencer no presente, foi criada uma variável dummy, na qual 1 = subiu de classe e $0=$ não subiu de classe.

A insatisfação/satisfação social é aqui operacionalizada pela seguinte pergunta: "Em geral, até que ponto o/a sr./sra. está satisfeito com sua vida?". O objetivo é apreender o descontentamento individual de forma ampla, capaz de englobar diversos tipos de frustração que podem motivar os protestos.

Foram incluídas como controles nos modelos de regressão algumas das principais variáveis que se mostram correlacionadas com a participação em protestos nos estudos mais relevantes sobre a participação política. São elas: anos de estudo, interesse por 
política, identificação partidária, eficácia política subjetiva interna e eficácia política subjetiva externa.

\section{Resultados}

Apresentamos, nesta seção, os resultados das análises descritivas e os modelos de regressão multivariados. É interessante observar que as taxas de ativismo em protesto sofrem alterações muito pouco significativas de 2006 a 2012 (Tabela 1):

Tabela 1

Frequência e proporção da participação em manifestação ou protesto público nos últimos 12 meses, Brasil, 2006, 2008, 2010 e 2012

\begin{tabular}{|l|c|c|c|c|c|c|c|c|}
\hline \multirow{2}{*}{} & \multicolumn{2}{|c|}{ 2006* } & \multicolumn{2}{c|}{2008} & \multicolumn{2}{c|}{2010} & $\mathbf{2 0 1 2}$ & \\
\cline { 2 - 9 } & Freq. & \% & Freq. & \% & Freq. & \% & Freq. & \% \\
\hline Sim & 60 & 5,09 & 81 & 5,71 & 146 & 5,94 & 64 & 4,62 \\
\hline Não & 1.119 & 94,91 & 1.337 & 94,29 & 2.311 & 94,06 & 1.320 & 95,38 \\
\hline Total & 1.179 & 100 & 1.418 & 100 & 2.457 & 100 & 1.384 & 100 \\
\hline
\end{tabular}

Fonte: Elaboração própria com base nos dados do Barômetro das Américas - Lapop, Brasil, 2006, 2008, 2010 e 2012.

* A onda de 2006 do survey no Brasil foi excepcionalmente aplicada em 2007.

Analisando a percepção de mudança de classe social, observa-se pela Figura 1 que, em 2012, a maior parte das pessoas (quase 70\%) declara ter se mantido na mesma classe entre os oito anos anteriores e a data da entrevista. Apesar disso, é considerável o fato de que um quarto dos entrevistados $(25,50 \%)$ percebeu que mudou para uma classe social superior. Completa esse quadro a relativamente pequena $(4,70 \%)$ proporção de pessoas que perceberam um movimento de queda entre as classes sociais: 
Figura 1

Proporção de pessoas por percepção de mudança de classe social, entre os oito anos anteriores e a data da entrevista, Brasil, 2012

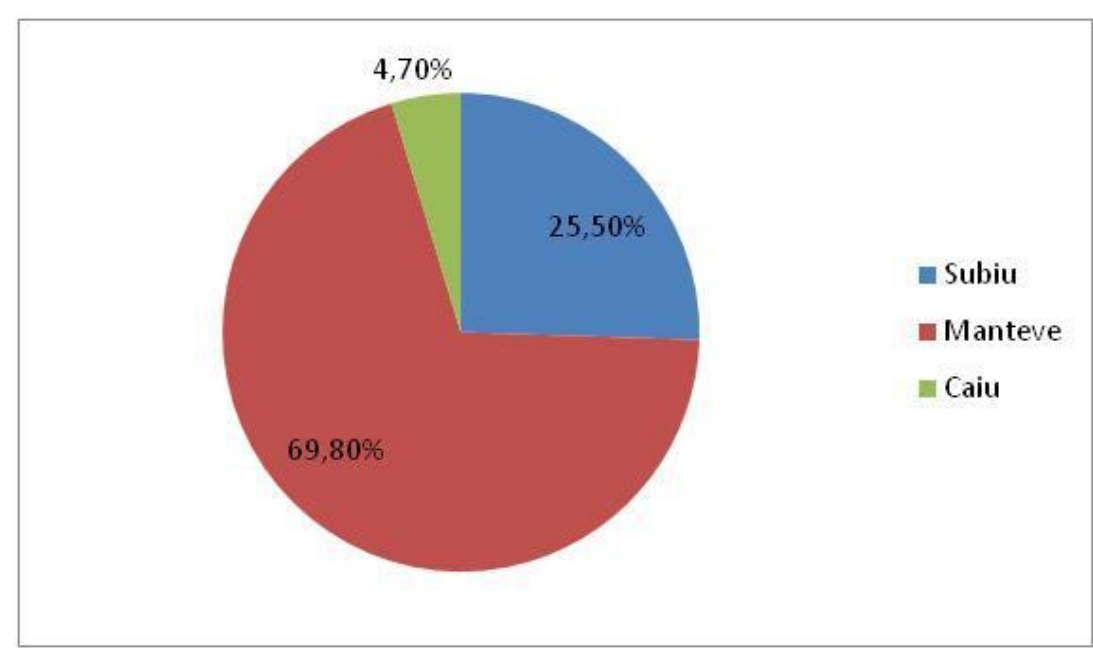

Fonte: Elaboração própria com base nos dados do Barômetro das Américas Lapop, Brasil, 2012. Observações: 1.384.

Foram elaborados dois modelos de regressão logística tendo a participação em manifestação ou protesto como variável independente, o primeiro sem interações (Tabela 2) e o segundo com os termos interativos das variáveis "insatisfação com a vida" e "mobilidade social" (Tabela 3). 
Tabela 2

Razões de chances estimadas por regressão logística para a participação em protesto ou manifestação nos últimos 12 meses, Modelo 1, Brasil, 2012

\begin{tabular}{|c|c|c|}
\hline $\begin{array}{c}\text { Variável } \\
\text { dependente }\end{array}$ & Variáveis independentes & $\begin{array}{c}\text { Modelo } 1 \\
\text { (razões de } \\
\text { chances) } \\
\end{array}$ \\
\hline \multirow{13}{*}{$\begin{array}{c}\text { Participação em } \\
\text { protesto ou } \\
\text { manifestação }\end{array}$} & Subiu de classe social & $\begin{array}{l}1,523^{*} \\
(0,424) \\
\end{array}$ \\
\hline & Muito satisfeito com a vida & <referência > \\
\hline & Pouco satisfeito com a vida & $\begin{array}{l}1,681 * * \\
(0,482)\end{array}$ \\
\hline & Pouco insatisfeito com vida & $\begin{array}{c}3,401 * * * \\
(1,464)\end{array}$ \\
\hline & Muito insatisfeito com a vida & $\begin{array}{c}1,136 \\
(1,203) \\
\end{array}$ \\
\hline & Ensino fundamental - até 8 anos de estudo & <referência > \\
\hline & Ensino médio - de 9 a 11 anos de estudo & $\begin{array}{c}1,496 \\
(0,492)\end{array}$ \\
\hline & Ensino superior - 12 ou mais anos de estudo & $\begin{array}{c}2,754 * * * \\
(1,021)\end{array}$ \\
\hline & Interesse por política & $\begin{array}{c}1,816 * * \\
(0,511) \\
\end{array}$ \\
\hline & Identificação partidária & $\begin{array}{c}1,235 \\
(0,341) \\
\end{array}$ \\
\hline & Eficácia política externa & $\begin{array}{l}0,866 * * \\
(0,0728) \\
\end{array}$ \\
\hline & Eficácia política interna & $\begin{array}{c}1,270 * * * \\
(0,106) \\
\end{array}$ \\
\hline & Observações & 1.384 \\
\hline
\end{tabular}

Fonte: Elaboração própria com base nos dados do Barômetro das Américas, Lapop, 2012.

Observação: Os coeficientes foram transformados em razões de chances (oddsratio). Erros-padrão entre parênteses.

Significância estatística unilateral: *** $\mathrm{p}<0,01, * * \mathrm{p}<0,05, * \mathrm{p}<0,1$.

De acordo com os resultados do Modelo 1 (Tabela 2), a percepção que se subiu de classe social apresenta relação estatisticamente significativa com o ativismo em protestos. Quem percebe ter mudado para uma classe social superior tem chance 1,5 vez maior de se envolver em protestos do que quem decaiu ou se manteve na mesma classe social, em um nível de significância de 10\%. Apesar de modesto, pode-se dizer que esse achado corrobora as teorias da privação relativa que colocam a percepção do horizonte do possível como fator importante para a magnitude da privação relativa e, consequentemente, para a participação em protestos políticos. De fato, os dados confirmam, no nível individual, a associação entre o horizonte do possível e o ativismo em protestos. 
A percepção sobre mudança de classe social está em consonância com o que efetivamente ocorreu no Brasil na última década. Partimos da constatação de uma melhora nas condições objetivas de vida de segmentos da sociedade brasileira desde o início dos anos 2000. Caracterizada, principalmente, pela diminuição da miséria, da desigualdade pessoal da renda no país e pelo aumento do poder aquisitivo das classes mais pobres de trabalhadores (Barros et al., 2010; Neri, Souza e Vaz, 2013), essa melhora de condições vem sendo atribuída tanto às políticas governamentais, como o aumento real do salário mínimo, a facilitação do crédito a camadas mais pobres da população, a ampliação do acesso à educação superior pública e os programas de distribuição de renda (Pochmann, 2010), quanto às mudanças na estrutura produtiva do país (Gaulard, 2011).

O mais importante para nossa análise é o simples fato de uma parcela considerável dos brasileiros reconhecer que suas condições de vida melhoraram sensivelmente nos últimos anos. Se os dados objetivos mostram melhorias em indicadores básicos de qualidade de vida e renda, especialmente das populações mais pobres, e se uma parcela significativa da população reconhece que ascendeu de classe social, é bem provável que o fenômeno em curso seja a ampliação do horizonte do possível. Para essas pessoas que detectaram melhorias em suas vidas a ponto de declarar que mudaram para uma classe social mais elevada, é esperado um incremento da percepção de que há condições para alcançar novas conquistas.

Esse aumento das expectativas foi ressaltado por Gurr (1971) como um dos principais fatores que levam os cidadãos a se rebelar contra o status quo. De fato, a relação da ascensão social com o ativismo em protestos nos leva a considerar que a privação relativa tem sido uma das condições propícias ao envolvimento nos protestos.

No Modelo 1, outro resultado que chama a atenção pela magnitude e significância é o da satisfação com a vida. Como esperado, a insatisfação relaciona-se com a participação em protestos, tornando-se maiores as chances de participar em protestos à medida que aumentam os níveis de insatisfação. Estar pouco satisfeito com a vida implica em chance 1,7 vez maior de participar em protestos em relação aos muito satisfeitos, a uma significância de $5 \%$. A categoria dos pouco insatisfeitos com a vida é a que apresenta o maior impacto sobre a participação em protestos dentre todo o modelo, com chance 3,4 vezes maior de participar em protestos em relação aos muito satisfeitos, em um nível de significância de $1 \%$.

A relação é tal como suposta pela teoria, com a insatisfação oferecendo motivação para o ativismo em protestos. No entanto, a relação entre a satisfação com a vida e o ativismo em protestos parece não ser linear, pois a taxa deste não continua a subir até a última categoria com a diminuição daquela, perfazendo uma trajetória parabólica. Parece haver um limite de insatisfação para além do qual seu impacto se 
inverte, passando a ser desmobilizador do ativismo em protestos, conforme argumentam Santos (2006) e Gurr (1971) a partir da tese do limiar de insensibilidade social.

A situação de extrema insatisfação com a vida parece mesmo ser pouco favorável à participação em protestos. As causas desse fenômeno ainda necessitam ser averiguadas. Pode ser que as pessoas muito insatisfeitas vislumbrem poucas chances de melhoria das suas condições e, por isso, não encontrem motivação para reivindicá-las publicamente. Ou ainda, que essas pessoas estejam mesmo em condições de extrema vulnerabilidade social, em que condições básicas de vida não estão disponíveis, não dispondo dos recursos necessários à participação.

Confirmada a associação entre, de um lado, o horizonte do possível e a insatisfação com a vida e, de outro, a participação em protestos, podemos passar ao segundo objetivo do artigo, que é entender se e como a relação entre as duas primeiras variáveis afeta o ativismo político. A hipótese de estudo nesse ponto é de que o impacto da insatisfação para a participação nos protestos é maior para aqueles que percebem um horizonte do possível. Com isso, esperamos que pessoas insatisfeitas, mas que percebem possibilidades de melhoria, protestem mais que as outras. O Modelo 2 (Tabela 3) apresenta as interações entre o horizonte do possível e a insatisfação com a vida: 
Tabela 3

Razões de chances estimadas por regressão logística para variável dependente participação em protesto ou manifestação nos últimos 12 meses, Modelo 2, Brasil, 2012

\begin{tabular}{|c|c|c|}
\hline $\begin{array}{l}\text { Variável } \\
\text { dependente }\end{array}$ & Variáveis independentes & $\begin{array}{c}\text { Modelo } 2 \\
\text { (razões de } \\
\text { chances) }\end{array}$ \\
\hline \multirow{16}{*}{$\begin{array}{l}\text { Participação em } \\
\text { protesto ou } \\
\text { manifestação }\end{array}$} & Não subiu de classe*Muito satisfeito com a vida & <referência> \\
\hline & Não subiu de classe*Pouco satisfeito com a vida & $\begin{array}{c}1,695^{*} \\
0,593 \\
\end{array}$ \\
\hline & Não subiu de classe*Pouco insatisfeito com vida & $\begin{array}{l}2,528 * * \\
(1,340)\end{array}$ \\
\hline & Não subiu de classe*Muito insatisfeito com a vida & $\begin{array}{c}1,70 \mathrm{e}-06 \\
(0,00145)\end{array}$ \\
\hline & Subiu de classe social*Muito satisfeito com a vida & 1,296 \\
\hline & Subiu de classe*Pouco satisfeito com a vida & 0,967 \\
\hline & Subiu de classe*Pouco insatisfeito com a vida & 2,978 \\
\hline & Subiu de classe*Muito insatisfeito com a vida & $4.457 e+06$ \\
\hline & Ensino fundamental - até 8 anos de estudo & <referência> \\
\hline & Ensino médio - de 9 a 11 anos de estudo & $\begin{array}{c}1,465 \\
(0,483) \\
\end{array}$ \\
\hline & Ensino superior - 12 ou mais anos de estudo & $\begin{array}{c}2,758^{* * *} \\
(1,025) \\
\end{array}$ \\
\hline & Interesse por política & $\begin{array}{l}1,821 * * \\
(0,515)\end{array}$ \\
\hline & Identificação partidária & $\begin{array}{c}1,259 \\
(0,349) \\
\end{array}$ \\
\hline & Eficácia política externa & $\begin{array}{c}0,872^{*} \\
(0,0732) \\
\end{array}$ \\
\hline & Eficácia política interna & $\begin{array}{c}1,287 * * * \\
(0,109)\end{array}$ \\
\hline & Observações & 1.384 \\
\hline
\end{tabular}

Fonte: Elaboração própria com base nos dados do Barômetro das Américas, Lapop, 2012.

Observação: Os coeficientes foram transformados em razões de chances (oddsratio). Erros-padrão entre parênteses.

Significância estatística unilateral: *** $\mathrm{p}<0,01, * * \mathrm{p}<0,05, * \mathrm{p}<0,1$.

A interação entre a ascensão de classe social e a insatisfação não apresentou os resultados esperados pela teoria, segundo a qual os que subiram de classe social e se sentem insatisfeitos com a vida teriam maior propensão ao envolvimento em protestos. Ao contrário do que se esperava, a percepção do horizonte de possibilidades combinada com a insatisfação com a vida não é responsável por um maior ativismo em protestos. 
Nenhuma das categorias dentre os que declararam subir de classe social mostra ter relação estatisticamente significativa com os protestos. A relação estatisticamente significativa ocorre somente entre aqueles que não subiram de classe social e se encontram nos níveis de relativa insatisfação com a vida.

Pode ser então, como supôs Gurr (1971), que a relação seja de causalidade indireta da privação relativa, mediada pela insatisfação antes de ter impacto sobre o ativismo em protestos. Para testar essa hipótese seria necessária a utilização de uma medida mais completa e adequada da privação relativa, capaz de captar a existência do hiato entre o real e o desejado. Para tais propósitos, a variável para medir o horizonte do possível precisa ser refinada, de forma a incluir, entre aqueles que realizaram o movimento ascendente, apenas os indivíduos que perceberam a possibilidade de alcançar condições ainda melhores. As limitações do nosso estudo, associadas às variáveis disponíveis, não permitem avançar nessa direção.

Apesar disso, os resultados deste estudo trazem indícios para que seja confirmada a relação entre a privação relativa, modificada pela ampliação do horizonte do possível, e o ativismo em protestos no Brasil. Os que realizaram a ascensão social - e que, portanto, passaram a ter expectativas crescentes - são mais propensos ao ativismo em protestos no Brasil. Esse resultado contraria o senso comum, segundo o qual, controlando-se pelos níveis de satisfação, a ascensão social seria responsável por um maior conformismo com a situação vigente, deixando as pessoas longe do ativismo contestatório. Essa constatação reforça ainda mais a tese de que a ascensão social aumenta a privação relativa, responsável por um maior engajamento em protestos.

\section{Considerações finais}

O objetivo deste artigo é examinar a relação entre a privação relativa e o ativismo em protestos. A partir de uma delimitação mais precisa do conceito de privação relativa, tendo como referência os mecanismos que operam no nível individual, buscamos mensurar o efeito do horizonte do possível sobre o ativismo em protestos.

Nossa primeira hipótese foi a de que o horizonte do possível tem impacto relevante sobre a participação. Os resultados indicam que, de fato, a privação relativa apresenta relação positiva com o ativismo em protestos por meio do horizonte do possível.

Os resultados demonstram também que quem conta com níveis intermediários de insatisfação com a vida tem maiores chances de se envolver em protestos que aqueles que se situam nos extremos positivo ou negativo de satisfação. Os extremos de satisfação com a vida parecem ser desmobilizadores do ativismo em protestos. Isso reforça a tese de Santos a respeito do limiar da sensibilidade social, abaixo do qual prevalece a inércia, inibindo o envolvimento político. 
A hipótese de que o efeito da insatisfação sobre a participação em protestos é condicionado pelo horizonte do possível não foi comprovada em nosso estudo. A interação entre a ascensão de classe social e a insatisfação não apresentou os resultados esperados pela teoria, segundo a qual os que ascenderam socialmente e se sentem insatisfeitos com a vida teriam maior propensão a participar em protestos. Uma possível explicação para esse resultado é que o padrão da relação entre o horizonte do possível e a insatisfação na produção de efeitos sobre a participação não é de natureza condicional, mas sim o de cadeia de efeitos. Seguindo essa lógica, a ampliação do horizonte do possível desencadearia a insatisfação que, por sua vez, conduziria a um aumento do ativismo político.

Uma contribuição relevante deste artigo, e da agenda de pesquisa que se abre a partir dele, é o deslocamento do foco das condições objetivas para a dimensão subjetiva da privação relativa, a qual só pode ser analisada no nível do indivíduo. Quanto à abordagem fundamentada em dados agregados, um importante avanço na investigação dos determinantes objetivos e subjetivos da participação política seria a realização de estudos comparativos entre países.

Clarice Mendonça - Mestra pelo Departamento de Ciência Política. Faculdade de Filosofia e Ciências Humanas, Universidade Federal de Minas Gerais. E-mail: $<$ claricecm@gmail.com>.

Mario Fuks - Professor do Departamento de Ciência Política. Faculdade de Filosofia e Ciências Humanas, Universidade Federal de Minas Gerais. E-mail: <mariofuks@gmail.com>.

\section{Referências bibliográficas}

BARros, R. P., et al. Determinantes da queda na desigualdade de renda no Brasil [online], Ipea, Texto para Discussão, n 1.460, Rio de Janeiro, jan. 2010. Disponível em:

<http://www.en.ipea.gov.br/agencia/images/stories/PDFs/TDs/td_1460.pdf>. Acesso em: 29 nov. 2013.

GAUlARD, M. "Balance sobre la cuestión de las desigualdades en Brasil". Problemas de Desarrollo, p. 111-134, jul.-set. 2011.

GURR, T. R. "Psychological factors in civil violence". World Politics, vol. 20, n², p. 245-278, jan. 1968. Why men rebel. Princeton, New Jersey: Princeton University Press, 1971.

LONG, J. S.; FREESE, J. Regression models for categorical dependent variables using stata. Texas: Stata Press, 2001.

Merton, R. K. Sociologia: teoria e estrutura. São Paulo: Editora Mestre Jou, 1970. 
Neri, M.; SouzA, P. F.; VAZ, F. Pobreza e desigualdade: duas décadas de superação. Primeiras análises Ipea da PNAD 2012 [online]. Comunicado Ipea 159, 2013. Disponível em:

<http://www.ipea.gov.br/agencia/images/stories/PDFs/comunicado/131001_comunicadoipea159_ap resentacao.pdf>. Acesso em: 29 nov. 2013.

Pochmann, M. "Novo padrão de mudanças sociais no Brasil". Nueva Sociedad. Edição especial em português, p. 109-133, dez. 2010.

RUNCIMAN, W. G. Relative deprivation and social justice: a study of attitudes to social inequality in twentieth-century England. Berkeley: University of California Press, 1966.

Santos, W. G. Horizonte do desejo: instabilidade, fracasso coletivo e inércia social. Rio de Janeiro: Editora FGV, 2006.

Tocqueville, A. O Antigo Regime e a Revolução. São Paulo: WMF Martins Fontes, 2009.

Verba, S.; Schlozman, K. L.; Brady, H. E. Voice and equality: civic voluntarism in American politics. London: Harvard University Press, 1995.

The unheavenly chorus: unequal political voice and the broken promise of American democracy. Princeton: Princeton University Press, 2012.

\title{
Resumo
}

A privação relativa e o ativismo em protestos no Brasil: uma investigação sobre o horizonte do possível

Este artigo analisa a relação entre a privação relativa e a participação política em protestos no Brasil, buscando entender o papel específico da percepção da ampliação do horizonte de possibilidades para o comportamento político contestatório. A privação relativa é aqui entendida como "resultado de uma percepção de carências, relativas a outros que não as sofrem, carências que não deveriam existir ou que podem desaparecer" (Santos, 2006, p. 148). O hiato entre o lugar social ocupado e o patamar que o indivíduo avalia que pode alcançar se intensifica quando ocorre a ampliação do horizonte de possibilidades, ou seja, da percepção de que essa progressão na condição de vida é factível. Quanto maior o hiato, maior a probabilidade de envolvimento em protestos (Gurr, 1971). A partir dos dados do survey Barômetro das Américas 2012, constatou-se que a ampliação do horizonte do possível está de fato relacionada ao ativismo em protestos, corroborando a hipótese de que a privação relativa, na recente história do Brasil, tem influência importante sobre o ativismo político.

Palavras-chave: privação relativa; protestos; horizonte de possibilidades; participação política

\begin{abstract}
The relative deprivation and the activism in protests in Brazil: an investigation about the horizon of possibilities

This article analyzes the relationship between relative deprivation and political participation in protests in Brazil, seeking to understand the specific role of the widening of the horizon of possibilities for contesting political activism. The relative deprivation is here understood as "the result of a perception of needs, comparing to others that don't have them, needs that should not exist or that may disappear" (Santos, 2006, p. 148). The gap between the social place one occupies and the level a person assesses that can be reached intensifies when there is expansion of the horizon of possibilities, in other words, the perception that this progression in living conditions is
\end{abstract}


feasible. The larger the gap, the greater the likelihood of engaging in protests (Gurr, 1971). Using Americas Barometer 2012 survey, it was found that the expansion of the horizon of possibilities is in fact related to activism in protests, supporting the hypothesis that the relative deprivation, in the recent history of Brazil, has important influence on political activism.

Keywords: relative deprivation; protests; horizon of possibilities; political participation

\section{Resumen}

La privación relativa y el activismo en protestas en Brasil: una investigación sobre el horizonte de lo posible

En este artículo se analiza la relación entre la privación relativa y la participación política en las protestas en Brasil, buscando entender el papel específico de la percepción de ampliar el horizonte de posibilidades para la conducta política contestataria. La privación relativa se entiende aquí como "el resultado de unas deficiencias percibidas en relación a los demás, deficiencias que no deberían existir o que puedan desaparecer" (Santos, 2006, p. 148). La brecha entre el lugar social ocupado y el nivel que el individuo estima que puede alcanzar se intensifica cuando hay expansión del horizonte de posibilidades, es decir, de la percepción de que esta progresión en las condiciones de vida es factible. Cuanto mayor sea la diferencia, mayor es la probabilidad de participar en protestas (Gurr, 1971). A partir de los datos del estudio Barómetro de las Américas 2012, se encontró que la expansión del horizonte de lo posible está en relación con el activismo en las protestas, una confirmación a la hipótesis de que la privación relativa, en la historia reciente de Brasil, tiene una influencia importante en el activismo político.

Palabras clave: privación relativa; protestas; horizonte de lo posible; participación política

\section{Resumé}

La privation relative et l'activisme dans les manifestations au Brésil: une enquête sur l'horizon du possible

On analyse, dans cet article, la relation entre la privation relative et la participation politique lors de manifestations au Brésil, en cherchant à comprendre le rôle particulier de la perception de I'élargissement de I' horizon de possibilités sur le comportement politique contestataire. La privation relative est ici comprise comme "le résultat de la perception de manques, concernant d'autres personnes qui ne les ressentent pas, des manques qui ne devraient pas exister ou qui peuvent disparaître" (Santos, 2006, p. 148). L'écart entre le lieu social qu'occupe I'individu et le niveau qu'il estime pouvoir atteindre $s$ 'intensifie quand se produit l'élargissement de I'horizon de possibilités, c'est-à-dire quand il perçoit que cette progression de condition de vie est possible. Plus I'écart est grand, plus la probabilité de participer à des manifestations augmente (Gurr, 1971). À partir des données du sondage Barômetro das Américas 2012, on a constaté que I'élargissement de I'horizon du possible est, en fait, lié à l'activisme dans les manifestations, ce qui corrobore I'hypothèse selon laquelle la privation relative, au cours de I'histoire récente du Brésil, a une grande influence sur I'activisme politique.

Mots-clés: privation relative; manifestations; horizon de possibilités; participation politique

Submetido à publicação em dezembro de 2014. Aprovado para publicação em maio de 2015. 